\title{
Batatas Fritas, Uma História de Amor e Amizade
}

\author{
Claudia Silva Ribeiro Alves, \\ Universidade do Vale do Itajaí - Brasil \\ dinha.csra@gmail.com \\ Djeison Siedschlag, \\ Universidade do Vale do Itajaí - Brasil \\ djeison.s@univali.br \\ Sidnei Vieira Marinho, \\ Universidade do Vale do Itajaí - Brasil \\ sidnei@univali.br \\ Anete Alberton \\ Universidade do Vale do Itajaí - Brasil \\ anete@univali.br
}

\section{Resumo}

O presente caso para ensino trata de uma história real de uma indústria fabricante de batatas fritas constituída na cidade de Itajaí/SC, idealizada e fundada por Silvio Zaguini em 26 de dezembro de 1989, que transformou uma pequena fábrica de batata palha em uma grande marca reconhecida no mercado catarinense. No entanto, a trajetória da empresa é marcada por momentos de amor e sofrimento, especialmente no ano de 2003, quando se depara com uma importante perda na família que desestrutura emocionalmente os sócios da empresa. Apesar da indústria apresentar resultados financeiros positivos e estar ampliando seu negócio, Silvio decide vender a marca para seu amigo Odemar Müller, proprietário da empresa DMüller, voltada para outro ramo de atividade comercial. A Distribuidora Müller foi fundada em o6 de setembro de 1965 e é líder no mercado em que atua, além de possuir solidez financeira e ser reconhecida no estado pela sua capacidade instalada, tecnologia, logística e comprometimento com seus clientes. A história de amizade e respeito envolve a venda da empresa para seu grande amigo e proprietário da distribuidora e o dilema na 
condução de negócios distintos. Este caso real coloca os estudantes frente a questão de tomada de decisão estratégica e mercadológica.

Palavras-chave: caso para ensino, batatas fritas, estratégia. 


\title{
Fried Potatoes, A History of Love and Friendship
}

\author{
Claudia Silva Ribeiro Alves, \\ Universidade do Vale do Itajaí - Brasil \\ dinha.csra@gmail.com \\ Djeison Siedschlag, \\ Universidade do Vale do Itajaí - Brasil \\ djeison.s@univali.br \\ Sidnei Vieira Marinho, \\ Universidade do Vale do Itajaí - Brasil \\ sidnei@univali.br \\ Anete Alberton \\ Universidade do Vale do Itajaí - Brasil \\ anete@univali.br
}

\begin{abstract}
The present teaching case is about a real history of a fried potato industry in Itajaí/SC (Brazil) idealized and founded by Silvio Zaguini on December 26 of 1989. He transformed a small fried potato factory in a big brand recognized in Santa Catarina's (Brazil) market. However, the factory trajectory is highlighted by moments of love and suffer, especially in 2003 when the factory faces with a big family loose that emotionally destabilize the company owners. Although the factory's positive financial results and business increasing, Silvio decided to sell the brand of his friend Odemar Müller-owner of DMüller companyoriented to another commercial activity. Müller's company was founded on December o6 of 1965 and is the leading company in its market. It has financial solidity and is recognized in its state by its size, technology, logistics, and commitment to its clients. The history of friendship and respect involve the sale of the company to its great friend and owner of DMüller and the dilemma in the business management of different companies. This real case offers to the students in front of the question of strategic and market decision-making process.
\end{abstract}

Keywords: Teaching case, fried potato, strategy. 


\section{Os personagens}

Nascido em o8 de junho de 1940 em Itajaí/SC em uma família tradicional da cidade, Sr. Silvio Zaguini foi criado com educação muito austera, estudava em colégio particular e ao longo do primeiro grau vivenciou a experiência de ser reprovado por 2 anos consecutivos. Seu pai, que procurava dar uma educação rígida aos filhos, ao concluir que Silvio não queria estudar, estabeleceu que o mesmo deveria mudar-se para Rio do Sul para um colégio interno que se localizava ao lado da igreja da cidade.

$\mathrm{O}$ adolescente embarcava no trem às segundas-feiras, pontualmente às $6 \mathrm{~h}$ da manhã, $\mathrm{e}$ seguia até Rio do Sul onde passava toda a semana imerso no colégio que contava na época com mais de 300 alunos internos. Após sair do internato, cursou o científico na cidade de Blumenau, porque não tinha em Rio do Sul e não queria estudar perto de casa por seu pai sempre ter sido um "cara durão”.

Quando terminou os estudos, trabalhava no Banco Inco e solicitou transferência para a cidade de Campinas/SP, livrando-se mais uma vez da rigidez e educação severa do pai. Tentou o vestibular de medicina, o qual reprovou e então decidiu fazer economia, o que o levou continuar a estudar e trabalhar em São Paulo.

Ao concluir a faculdade, voltou para Itajaí, onde começou a trabalhar em uma empresa como vendedor, passando a gerenciar a fábrica e também casou e teve dois filhos. Com maior experiência, ao retornar à cidade natal, Silvio Zaguini sabia que o exemplo da educação rígida do pai fora importante para sua formação profissional e principalmente por ter se tornado um homem íntegro e de caráter, que sempre valorizou a família e se dedicou ao trabalho.

Por outro lado, Odemar Müller, nascido em o7 de setembro de 1937, na cidade de Brusque/SC, iniciou seus estudos primários no grupo escolar Feliciano Pires e entre os anos de 1952 e 1955, trabalhou na empresa de seu pai no engarrafamento e distribuição de bebidas, e na oportunidade iniciou seu aprendizado como motorista em um velho caminhão.

Odemar, carinhosamente chamado de Milinha pelos amigos, não concluiu os estudos, mas seu compromisso militar foi cumprido no ano de 1956 , onde teve a oportunidade de protagonizar muitas histórias por ter cometido diversas indisciplinas. 
No ano de 1957 foi residir no Rio de Janeiro e ser motorista nas lotações da época, porém, em 1958 já estava de volta e recebeu o convite de gerenciar uma empresa que produzia e distribuía a marca de Café Nelson na cidade de Itajaí. Em o3 de novembro de 1962, casou-se com a então rainha dos comerciários de Brusque, Anna Maria e vieram morar definitivamente em Itajaí.

Após o início de suas atividades na distribuidora de café passou a acumular as funções de gerente, vendedor e entregador, permanecendo nesta condição até 1967. Foi então que em o6 de setembro de 1967 passou a distribuir produtos por conta própria, fundando uma pequena distribuidora que passaria a distribuir Café Nelson, Doces Chaves, Massas Todeschini e outros pequenos doces ensacados.

No mesmo ano, adquiriu o primeiro veículo financiado, depois com a aquisição da segunda Kombi houve a necessidade de contratar um funcionário que permaneceu ao seu lado até setembro de 2015 .

\section{A oportunidade}

O senhor Silvio Zaguini sempre foi uma pessoa observadora, se atentava em pequenos detalhes seja no trabalho ou na sua vida pessoal. Em certa ocasião na organização do casamento da filha, observou a ausência de um produto, não muito comum na época, que iria ressaltar a composição de alguns pratos, dando um toque e sabor diferente aos alimentos.

"No ano de 1988 minha filha mais velha se casaria, e como tivemos apenas dois filhos em nosso conluio matrimonial, uma menina chamada Alice e um menino chamado Fernando, eu quis participar de cada detalhe da recepção dos convidados, desde a composição do cardápio e as demais minúcias para me assegurar que tudo sairia perfeito, até porque era minha 'princesinha' que estaria casando".

Uma das grandes preocupações do senhor Silvio era ter um jantar impecável para ser saboreado pelos convidados que foram criteriosamente selecionados entre amigos íntimos e familiares.

"Quando analisei o cardápio junto ao restaurante que os convidados e familiares seriam recepcionados questionei por que não incluíram batata palha em alguns pratos, 
porque para a época era um ingrediente que daria um toque todo especial na composição dos alimentos, além de ser algo totalmente 'diferente”.

O mestre, responsável pela composição dos pratos, afirmou que realmente ficaria perfeito, porém, teria que buscar o alimento em uma empresa fabricante de batata palha que ficava localizada na cidade de Balneário Camboriú, pois o restaurante não dispunha deste produto. Não era algo comum na ocasião, por isso os restaurantes não tinham por hábito colocar no cardápio. Como Silvio Zaguini queria muito o produto procurou palha na fábrica produtora.

Ao chegar no local onde o cozinheiro indicara, o senhor Silvio se deparou com condições lastimáveis de higiene e limpeza. As batatas eram industrializadas em uma casa, de uma forma bastante rústica, porém, totalmente inadequada. As batatas eram cortadas em uma máquina velha e esta era apoiada em cima de um vaso sanitário.

"No primeiro momento eu 'me apavorei' porque comecei a observar outros detalhes, como a fritura em condições assustadoras. Quanto a fábrica ser rústica, não via nenhum problema, mas as condições de higiene são primordiais para qualquer negócio! Desisti imediatamente da compra, porém, insisti buscando informações de outras empresas produtoras de batata palha e descobri outra fábrica em Florianópolis, na qual também busquei conhecer a origem do produto, até porque na primeira não tive uma boa experiência das condições do alimento".

Silvio Zaguini estava feliz com a aquisição do produto encontrado na capital e com o toque especial que as "batatas palhas" dariam aos pratos no dia da festa de casamento da "sua menina". Por outro lado, ficou intrigado com aquele alimento, pois a batata palha surgia como um produto inovador e que proporcionava um diferencial para diversos pratos. Com a possibilidade de utilizar o item em diversas composições, iniciou uma pesquisa sobre o mesmo.

"Depois de alguns dias, após a festa da minha filha, fiquei imaginando aquela fábrica em Balneário Camboriú e inconformado com a situação a qual havia 'experimentado' iniciei uma investigação para saber a respeito deste mercado de batata palha, público alvo, volume, fornecedores, etc., e ainda consegui identificar a quantidade de batatas que aquele produtor comprava para produzir a palha, e realmente era um volume razoável”. 
Após o levantamento dos dados, Silvio Zaguini percebeu que era um mercado promissor, que trazia retorno financeiro e que tinha um campo grande para ser explorado. Falou com si mesmo: "Eu vou fazer a palha". E assim, com entusiasmo e empenho, motivado pela parceria de sua esposa, em 26 de dezembro de 1989 nasce a Bavária Indústria e Comércio de Alimentos Ltda. na cidade em que nasceu, casou e criou seus filhos.

Montei a fábrica e começamos a produzir de forma artesanal as batatas palha, e os produtos eram feitos por linha de produção com profissionais que cuidavam da área de descasque, seleção, máquina de corte, havia ainda aqueles que as fritavam e salgavam de forma manual e após este processo o alimento seguia a linha de empacotamento, e fechamento das embalagens. Este processo produtivo ficava sob a responsabilidade da minha esposa para que todo o produto fosse envasado com qualidade".

Os produtos eram criteriosamente acompanhados pelo olhar detalhista de sua esposa, que estava junto com os funcionários em tempo integral, analisando cada detalhe. A higiene era fator preponderante de todos os empregados e em todos os processos da fábrica.

"Quando já estávamos com uma produção considerável de batata palha e tínhamos clientes específicos, iniciamos a fabricação da batata ondulada, porque identifiquei uma ótima oportunidade de mercado que iria agregar valor e também aumentaríamos o nosso portfólio de produtos”.

Era preciso abrir novos mercados e continuar com o crescimento da empresa e um novo produto parecia ser a estratégia adequada.

\section{Abrindo novos mercados}

Com o negócio estruturado e com possibilidade de crescimento, o próximo passo se concentrava em como ampliar os horizontes.

"Quando eu já estava com uma clientela fixa, observei que precisava abrir novos mercados, mas não poderia me dedicar a esta área, porque tinha que administrar os negócios que só cresciam, e a minha esposa, como sempre, estava focada e dedicada à fabricação dos produtos, era meu braço direito dentro da empresa, e com todo seu empenho envolvido nos interesses da família eu nunca me preocupei com a parte da produção e a qualidade dos produtos; éramos alma e coração”. 
Como a cidade de Itajaí era pequena naquela época, o senhor Silvio conhecia Odemar desde o tempo da juventude, dos bailes de sábado à noite, do futebol, do clube e tinham uma amizade de longa data. O Sr. Odemar sempre foi batalhador, iniciou as atividades da constituição de sua empresa com uma Kombi onde vendia seus produtos (guloseimas) durante a semana e passeava com a família e amigos nos finais de semana.

"Lembrei-me do amigo Odemar, que tinha uma distribuidora de alimentos bastante conceituada na cidade e que a sua empresa atuava em todo o estado de Santa Catarina e tinha certeza que colocando 'a minha batata' em suas mãos, eu ganharia ainda mais mercado, porque sabia que Milinha era influente, inclusive nas redes de supermercados nas quais eu ainda não havia inserido meu produto”.

A parceria dos amigos Odemar e Silvio deu certo e a amizade se fortaleceu ainda mais baseada no respeito e na confiança entre ambos os parceiros e as duas empresas. Como a empresa cresceu em relação a variedade e volume de produtos, com o passar do tempo foram comprados novos equipamentos, mais modernos e com maior capacidade produtiva, como máquinas automáticas para descascar e corte e enormes fritadeiras; investimentos necessários para atender a demanda do mercado, visto que alcançavam a marca aproximada de 20 toneladas de batatas por semana na linha de produção.

Silvio Zaguini era um profissional de visão de mercado, começou a adicionar itens no portfólio de seus produtos, como pipoca e castanha de caju que eram terceirizados, e ainda criou uma segunda linha de batatas onduladas (papas fritas) para atender consumidores das classes $\mathrm{C}$ e D. Ter um parceiro para a distribuição seria fundamental para a ampliação dos negócios atendendo a rede varejista no estado.

\section{A distribuição}

A batata palha vinha sendo comercializada exclusivamente no estado de Santa Catarina pela Distribuidora Müller que fazia um excelente trabalho de armazenagem e distribuição. Odemar e Silvio se tornavam cada vez mais parceiros fazendo grandes negócios.

Ao longo de sua história a DMüller, acumulou importantes conquistas, passando de um pequeno atacado de doces no Centro da cidade de Itajaí para uma empresa de grande representatividade no ramo de distribuição de alimentos representando marcas de destaque 
nacional e produtos exclusivos. Atualmente, com o apoio de uma infraestrutura que garante grande capacidade de armazenamento e um avançado sistema de logística, a empresa continua se modernizando, atendendo às demandas do mercado com competência e buscando a excelência em todas as suas operações.

Com toda a infraestrutura e responsabilidade que a Distribuidora Müller oferecia na pessoa do seu Odemar, Silvio tinha cada vez mais certeza de que o produto que fabricava estava sendo tratado de forma ética e responsável, e a maior prova era que o faturamento aumentava anualmente.

\section{A doença}

Os negócios estavam sendo promissores, crescendo, ampliando, atuando em novos mercados com outros produtos e com rentabilidade acima do esperado, foi quando o senhor Silvio Zaguini teve uma notícia que fez com que diminuísse sua rotina profissional. Em 1998 esteve muito doente, em um exame de rotina descobriu que estava com câncer no esôfago. O senhor Silvio Zaguini sempre foi uma pessoa de garra, determinado e corajoso, principalmente no que se referia à saúde. Por ser bastante consciente, não se deixou abalar com a notícia.

As complicações relacionadas à saúde do senhor Silvio Zaguini não paravam por aí, foi quando ao realizar os exames pré-operatórios seu coração apresentou complicações. O senhor Silvio Zaguini não podia perder tempo, tinha prazo para concluir os exames para tratar o câncer e agora buscava recurso para tratar seu coração.

Realizou primeiramente a cirurgia do coração e na sequência a retirada do câncer no esôfago. Não bastasse esses dois procedimentos delicados pelos quais o senhor Silvio Zaguini passou em um curto espaço de tempo, foi diagnosticado uma broncopneumonia. Realizou o tratamento no Hospital do Pulmão na cidade de Blumenau e desde então realiza periodicamente exames preventivos.

Estes obstáculos foram um incentivo ao senhor Silvio Zaquini para continuar a dedicação a família e aos negócios.

\section{A perda}


Depois de longo período de intensivo tratamento de saúde, em 1998 Silvio Zaguini sentia-se bastante disposto e ansioso para retornar às atividades profissionais como antes. Queria retomar os negócios, voltar a se reunir com os amigos, visitar os distribuidores e cuidar de sua família.

Quando os negócios estavam prosperando, depois de alguns anos de muito trabalho, Silvio Zaguini resolveu adquirir um novo terreno na Rodovia Jorge Lacerda para construção e ampliação da fábrica, tendo ao seu lado a esposa que continuava ajudando e o filho que também era um grande parceiro.

“Na época que estava investindo na nova fábrica minha esposa ficou muito doente e quem começou a tratar dela foi um médico 'da minha loja'. Eu não gostava muito deste profissional como médico, porém, como amigo, não tinha nada contra. Este especialista apenas dizia que não era nada grave, que não precisávamos nos preocupar e eu 'cismado' dizia: como não é nada grave doutor? Deve haver algum problema, precisamos fazer uma investigação mais profunda”.

A esposa do seu Silvio entrou em cirurgia, fez o procedimento necessário e ficou uns 20 dias internada recebendo doses fortes de quimioterapia e ele e o filho iam todos os dias ao hospital em Blumenau. Após a cirurgia, o Dr. Machado começou a cuidar dela também e o hospital Santa Catarina, no qual estava sendo realizado todo o tratamento, começou a preocupar-se com o senhor Silvio Zaguini e a fazer o acompanhamento psicológico por duas horas diárias, conversando, orientando e "preparando-o para o pior".

Apesar da vontade de viver, a doença venceu e a esposa faleceu em 2003, e o senhor Silvio viveu a experiência com a companheira desde o diagnóstico do câncer até a sua morte. Esteve ao seu lado todos os dias no quarto do hospital, na quimioterapia, nos momentos de dor, de angustia e agora era o momento de aprender a seguir sozinho. A esposa o ajudava muito, acompanhando e exigindo produção e qualidade e em função disso seu Silvio Zaguini desgostou dos negócios.

\section{A tomada de decisão}


Após o falecimento da esposa alguma coisa dentro do senhor Silvio Zaguini havia “quebrado". Ir para a fábrica exigia uma força física e psicológica que parecia um fardo pesado que o senhor Silvio não conseguia mais suportar.

"Certo dia, quando estava sozinho olhando para aquela fábrica enorme e vazia, peguei o telefone e liguei para meu grande e velho amigo e disse: 'Odemar, vem cá, tu não queres comprar a minha fábrica de batatas e a marca?" Sei que se ligasse para uma empresa que já andava me assediando eu venderia imediatamente e até por um preço melhor, mas como eu tinha carinho pela marca, pelo produto e por toda história construída no enlace de minha família, preferia 'passar' os negócios para alguém conhecido que eu tinha consideração inestimável, porque foi quem alavancou a minha empresa e fez com que o produto ficasse conhecido em todo estado de Santa Catarina”.

O senhor Silvio Zaguini agendou um horário e uma visita na nova indústria de batatas com os empresários de São Paulo, estes estavam dispostos a comprar a fábrica, ofereciam garantias, prometiam pagar um valor "considerável”, além de terem recursos para adquirir o estabelecimento completo como galpão, máquinas e equipamentos e a marca "à vista”, em espécie.

O senhor Odemar, distribuidor das batatas fritas do senhor Silvio quando recebeu o telefonema do amigo ficou muito pensativo e tinha dúvidas em relação a compra da fábrica e da marca, porque não era o foco do seu negócio. O senhor Odemar sempre foi acostumado a vender e a distribuir os produtos dos fabricantes, das indústrias, tanto é que continua distribuidor exclusivo de grandes marcas em todo o estado de Santa Catarina até os dias atuais. Outro fator importante da decisão era o investimento que o senhor Odemar estava decidindo fazer naquele ano de 2003. Ao trazer para o seu negócio um novo fornecedor e para abastecer os estoques dos novos produtos, necessitava de capital considerável, e comprar a marca de batatas fritas somente para ajudar o amigo poderia ser muito arriscado.

Como poderia o senhor Odemar de uma hora para outra focar em um negócio totalmente novo e fora da sua realidade?

Comovido com a situação o senhor Odemar Müller então tomou a grande decisão de realizar a compra da empresa. O negócio foi realizado sem analisar muito o mercado, e assim, foi vendida a marca de batata palha e batata ondulada e alguns equipamentos, mais por uma história envolvida e embasada no amor e na amizade do que qualquer outro fator. 
Milinha queria que a marca que havia ajudado a "construir" no mercado de atuação da Distribuidora Müller em Santa Catarina, permanecesse ainda mais forte. Ele considerava que adquirindo uma marca própria, o produto viria agregar os negócios da família Müller. Os amigos buscaram uma cooperativa agrícola que plantava batatas em Castro no Paraná e o senhor Silvio Zaguini cumpriu a promessa de ajudar o amigo Odemar, desde que este continuasse com os produtos, e a marca.

Odemar Müller desconhecia as oportunidades e ameaças desse novo negócio, portanto, buscou trabalhar na elaboração de um plano para a reestruturação e alocação de recursos. Os desafios apenas iniciavam nesta nova etapa, a definição dos objetivos e a visão do novo negócio seria crucial para a continuidade e sustentabilidade da empresa. Era necessário conhecer o ambiente e a concorrência e estabelecer estratégias para a ampliação das vendas do produto no comércio. O mercado contava com um grande líder do segmento (batatas) e a marca era pouco reconhecida.

Estes fatos limitavam os preços das batatas frente aos concorrentes e além disso parte do processo de produção era manual o que elevava os custos de produção. Mesmo com diversas barreiras que se apresentavam, Milinha tinha uma visão de futuro e agora precisava administrar dois negócios, a distribuição e a produção de um produto exclusivo.

Naquela época, o cenário da distribuição passava por grandes mudanças. A internet, por exemplo, que permitia uma forma eficiente e barata de comunicação, possibilitava ao próprio cliente comprar diretamente da fábrica. Essa compra direta permitia várias vantagens com a eliminação de intermediários e trazia ao fabricante a possibilidade de uma maior margem de lucro com um menor preço para o consumidor final.

Por outro lado, a necessidade de atendimento a curtos prazos de entrega e a impossibilidade da indústria atender a pequenos pedidos e com rapidez fizeram com que as novas empresas da internet percebessem rapidamente que, para a sua continuidade, precisariam de centros de distribuição e sistemas de gestão de estoques eficientes, seguindo o modelo tradicional de distribuição.

No contexto da produção de um produto exclusivo os desafios eram ainda maiores, e se concentravam em manter a qualidade do produto para se diferenciar no mercado. Milinha sabia que este era o caminho, um produto com qualidade superior aos concorrentes 
ampliaria as vendas em conjunto com a distribuição do portfólio de produtos já trabalhados pela Distribuidora Müller.

A praça, público alvo, segmentação de clientes, a produção, o marketing, a qualidade, vários fatores podem influenciar para o sucesso ou fracasso de um novo produto e da empresa. E agora? Como estruturar, manter e ampliar a nova configuração deste negócio frente aos desafios do mercado?

\section{Notas de ensino}

\section{Objetivos educacionais do caso}

O caso "Batatas fritas, uma história de amor e amizade" tem por objetivo levar os alunos ou profissionais de empresas a vivenciar decisões estratégicas e de marketing, analisando as ameaças e oportunidades na diversificação dos negócios, aumento do portfólio dos produtos, etc.

\section{Utilização recomendada}

O caso batatas fritas, uma história de amor e amizade foi desenvolvido para ser utilizado em cursos de graduação em disciplinas relacionadas a marketing e estratégias organizacionais, além de poder ser utilizado em treinamentos de gestores em empresas de pequeno e médio porte.

\section{Fonte de obtenção dos dados do caso}

Os dados primários foram obtidos em entrevista pessoal com o Sr. Silvio Zaguini no dia 22 de dezembro de 2015 com início às 15h e duração aproximada de três horas, proprietário da Bavária Indústria e Comércio de Alimentos Ltda. e também por meio de entrevista pessoal para complemento e cruzamento de informações com o Sr. Odemar Müller, proprietário da empresa Distribuidora Müller Comércio e Representações Ltda no dia 23 de dezembro de 2015, com início 15 h3o e duração aproximada de duas horas. Os dados 
primários foram complementados com dados secundários com relatórios gerenciais da empresa Distribuidora Müller e álbum com informações da história do senhor Odemar Müller.

\section{Questões para discussão}

As respostas das questões devem ser relacionadas ao caso de ensino.

1. Na posição do senhor Odemar Müller e considerando uma decisão estratégica, você compraria a fábrica do amigo para ajudá-lo, ou investiria no seu negócio? Justifique a resposta.

2. Com a aquisição, como poderia o senhor Odemar posicionar a nova empresa considerando os 5 P's proposto por Mintzberg (2006)?

3. Quais seriam as ameaças e oportunidades para a empresa compradora deste novo negócio?

4. Qual a estratégia de marketing que poderia ser implementada para os novos produtos?

\section{Análise do caso}

Pode-se começar a discussão do caso abordando aspectos relacionados a decisões estratégicas e ações de marketing que podem influenciar o desenvolvimento da empresa, orientando os alunos ou funcionários a preparação para este novo mercado.

\section{Decisões estratégicas}

A tomada de decisão feita pelo senhor Odemar Müller considerou mais a amizade do que um estudo sobre ganhos e perdas na aquisição da empresa. Neste contexto, foi abordada uma breve discussão a respeito de estratégias e decisões estratégicas, ameaças e oportunidades de mercado.

Estratégia é um padrão de decisões que determinam e revelam seus objetivos, produzem as principais políticas e planos, identificam o segmento de negócio no qual a empresa está, o tipo de organização econômica e humana que ela é ou pretende ser e a 
natureza das contribuições econômicas e não econômicas a serem oferecidas aos acionistas, empregados, clientes e à comunidade (Andrews, 1980).

Na ocasião da compra da empresa o senhor Odemar Müller não tinha definido um conjunto de objetivos e as estratégias eram deliberadas. Por outro lado, o senhor Müller tinha o conhecimento, ainda que empírico, que aquela decisão traria uma vantagem competitiva. A estratégia é uma manobra para atingir uma vantagem competitiva, pelo bom posicionamento da empresa em um setor econômico na qual se insere, graças ao bom conhecimento da cadeia de valor (Porter, 1986).

A decisão da compra da empresa foi tomada de forma consciente e com propósitos de longo prazo para ampliar os resultados. A estratégia busca posicionar a organização no ambiente em que está inserida. Na literatura existem diversas definições de estratégia. O reconhecimento dessas múltiplas definições pode ajudar as pessoas a moverem-se neste campo (Mintzberg, 2006).

\section{Análise estratégica na visão de Mintzberg}

Com a aquisição do novo negócio, o próximo passo foi trabalhar na elaboração de um plano com a reestruturação e alocação de recursos e a definição dos objetivos e estratégias para o novo negócio. O objetivo da empresa era a distribuição de produtos e não a produção, desta forma buscou-se a terceirização com a escolha de um fornecedor que entregasse o produto acabado. Com esta medida houve a eliminação por completo do processo industrial, uma vez que não era de conhecimento da equipe interna da DMüller e a definição foi de não manter este processo.

Como manobra para superar a concorrência buscou-se o aumento da margem comercial por meio de diferenciais de qualidade do produto, marketing e serviço de atendimento ao consumidor (SAC). Para o posicionamento do novo produto no mercado foi lançada a marca Slice (batata ondulada) com embalagens atrativas e diferenciadas e que agregou ao faturamento das batatas fritas.

Na literatura sobre estratégia, Mintzberg (2006) tem um enfoque para a análise de estratégia conhecido como os cinco "Ps": 1) Plano (plan) a estratégia envolve a adoção de um curso intencional de ação e a alocação de recursos para alcançar os objetivos de longo prazo 
da organização; 2) Pretexto ou estratagema (ploy) manobra específica para superar concorrente; 3) Padrão (patern) refere-se à consistência no comportamento organizacional podendo ser pretendida ou não; 4) Posição (position) refere-se à interligação da organização com o seu ambiente, sendo este caracterizado pela mudança, incerteza, concorrência e competitividade, onde o ambiente não é controlável; 5) Perspectiva (perspective) representa a maneira da organização visualizar o mundo, uma vez que a estratégia é uma abstração fundamental que seja uma perspectiva compartilhada.

\section{Marketing e compostos}

Com a aquisição da nova empresa e consequentemente novos produtos, o senhor Ode mar contratou uma agência para dar suporte na área de marketing, criando novas embalagens, materiais de merchandising, ações nos pontos de vendas (PDV) e ações com os consumidores e clientes. Por ser uma empresa comercial, as teorias do marketing muitas vezes foram desprezadas gerando dificuldades de criar e executar os planos de longo prazo.

No contexto atual, as empresas buscam alternativas para maximizar os resultados frente a concorrência. Assim, os “4Ps” (Produto, Preço, Praça e Promoção), norteiam a elaboração de uma estratégia de marketing.

Na definição do produto a empresa Distribuidora Müller buscou oferecer algo de maneira diferente e melhor no mercado, foi trabalhado o design, reestruturado a embalagem, revisto processo de produção e fornecedores. Para o produto batatas palhas foi criado embalagens que apresentassem a qualidade do produto (embalagem com janela), na sequencia foi evoluído para embalagens que garantisse maior conservação (embalagem metalizada) e com sugestões de ambientes de consumo (refeições que utilizem batata palha).

Já no produto batata ondulada os desafios foram grandes. A criação da marca Slice, e novas embalagens atrativas. Para a criação da marca buscou-se um nome jovem, que tivesse ligação com a categoria (Slice significa fatia em inglês), procurou-se junto ao fornecedor criar um produto que diminuísse a sensação de oleosidade e sódio, mantendo a "crocância" e uma aparência de fatias de batatas maiores e sem "pontos pretos". Também foi diferenciado 
a cor das embalagens, predominante azul para a categoria, com as embalagens na cor laranja num movimento psicodélico.

Em termos de preço a estratégia adotada foi a terceirização da produção para baixar os custos sem alterar a qualidade dos produtos. No produto batata palha, por possuir uma situação mais confortável em relação as vendas, distribuição e principalmente a qualidade, foi definido que a marca não iria brigar por preço baixo. Era preciso rentabilizar para investir na marca.

Para o produto batata ondulada (Slice), a estratégia foi bem diferente. "Tínhamos um preço abaixo do líder ( $\mathrm{R} \$ 0,50$ - 30\% abaixo) e quanto mais ganhávamos marketshare, mais poderíamos rentabilizar". O cuidado foi tomado para que o mercado não intitulasse de "produto barato". Desta forma a estratégia adotada foi manter o preço abaixo e acompanhar os preços praticados pelo líder de mercado para que esta diferença não aumentasse. Como a distribuidora já revendia o produto, a praça já estava estabelecida contemplando todo o estado de Santa Catarina para grandes redes de supermercados, médios mercados e clientes do pequeno varejo.

“Sem dúvida isto foi um enorme facilitador. Nós já tínhamos os volumes vendidos, o preço de custo, o preço de venda, os investimentos em marketing feitos pelo fabricante, o know-how de mais de 5 anos vendendo os produtos deste fabricante e um forte relacionamento com os clientes. Facilitou os cálculos para identificar o prazo de payback e fechar o negócio".

No campo dos estudos sobre o marketing e a definição correta do produto, preço, praça e promoção evidenciam como importância fundamental para o sucesso da empresa em um ambiente competitivo. O marketing moderno exige mais do que desenvolver um bom produto, estabelecer preços atraentes e torná-lo acessível aos clientes-alvo. As empresas precisam se comunicar com as partes envolvidas e com o público em geral (Kotler, 2000).

\section{Dados atuais do caso}

A marca da batata palha (Kifritas) continua com o mesmo nome até os dias atuais e teve consideráveis modificações na embalagem, alterou a gramatura e corte do produto com 
embalagem tradicional ou extrafina de 8 ogr e a econômica de 4oogr. A Kifritas tradicional é indicada para pratos diversos como: strogonoff, escondidinho entre outros e a Kifritas extrafina indicada para cachorro quente por ser uma batata com um corte mais fino e mais adequado para lanches e crianças e é batata firme, que não amolece. 


\section{Referências}

Andrews, K. R. (1980). The concept of corporate strategy. In H. Mintzberg, J. B. Lampel, J. B. Quinn, \& Ghoshal. The strategy process: concepts and contexts. Prentice Hall.

Kotler, P. (200o). Administração de marketing. (10. ed.). São Paulo: Pioneira.

Mintzberg, H. (2006). Cinco Ps para estratégia. In H. Mintzerg et al. O processo da estratégia: conceitos, contextos e casos selecionados. (4. ed.). Porto Alegre: Bookman.

Porter, M. E. (1986). Estratégia Competitiva: técnicas para análise da indústria e da concorrência. (7. ed.). Rio de Janeiro: Campus. 